Holti (March 16, p. 753) that it is so very rare; nor can I agree that the symptoms are always very dramatic. I cannot see anything unfortunate in the statement that "it has for long been known that infantile eczema may be caused by sensitization to the proteins of cows' milk." There is no suggestion in your annotation that milk allergy is the only cause, or the commonest cause, of infantile eczema.

I have never found that discussion of diet has created any anxiety in the minds of parents of eczematous children; rather the reverse, especially when it enables them to dispense with elaborate, time-consuming, and costly dressings.-I am, etc.,

Department of Dermatology,

United Birmingham Hospitals.

Bernard C. Tate.

\section{Unilateral Haematocolpos}

SIR,-I was very interested to read Mr. Michael Solomons's account of a case of unilateral haematocolpos associated with uterus didelphys (March 9, p. 659). I have seen two patients with unilateral haematocolpos but can find no reference to the condition in the literature.

My first case was in many ways similar to that reported by Mr. Solomons. A single girl aged 17 was seen on March 13, 1958, complaining of pain in the right groin for the past seven weeks. Since the menarche at 12 she had had normal periods until December, 1957. She had no loss in January or February and only a scanty one at the time of the expected period in March. She had no symptoms of pregnancy but admitted to regular coitus until a few weeks before her admission to hospital. On examination, a soft swelling was found arising from the pelvis and extending about 2 in. $(5 \mathrm{~cm}$.) above the symphysis pubis. On pelvic examination the vagina was patent on the right, but no cervix could be felt; the swelling extended down the anterior and left walls of the vagina to the introitus. A tentative diagnosis of some form of ectopic pregnancy was made and laparotomy performed. This showed the swelling to be vaginal in origin; a single cervix could be felt at the top of it, and above this were two uterine bodies. The swelling was needled and incised per vaginam; $1 \frac{1}{2}$ pints $(853 \mathrm{ml}$.) of stale blood escaped and the cervix could then be reached. It was dilated and a sound passed into each uterine horn confirming the diagnosis of uterus bicornis unicollis.

The patient failed to attend for follow-up and was not seen again until December, 1958. In the interim she had got married; after normal periods in April and May she had become pregnant in the right horn of the uterus. She went into labour spontaneously at 36 weeks and delivered a baby weighing $4 \mathrm{lb}$. $6 \mathrm{oz}$. $(1,984 \mathrm{~g}$.) as a breech. A few months later she again became pregnant in the right horn, and at 30 weeks delivered a baby weighing $2 \mathrm{lb}$. $15 \mathrm{oz}$. $(1,332$ g.) which presented as a vertex. In 1960 she had an abortion at 23 weeks.

The second case was in an unmarried girl aged 19. She was first seen on November 20,1962 , with a month's history of lower abdominal pain. She had recently had some nausea and constipation but no other symptoms. Since the menarche at 14 she had had regular normal periods, the last of which started on November 8. Abdominal examination revealed a soft swelling arising from the pelvis and reaching the umbilicus with a harder area to the right of the midline at the top. Vaginally, the swelling extended down to the introitus on the right side, there being a normal vagina on the left but the cervix could not be reached. Benefiting by experience of the previous case, a provisional diagnosis of unilateral haematocolpos was made. Examination under anaesthesia confirmed the findings, and after needling the swelling was drained from its lower pole, $26 \mathrm{oz}$. (739 ml.) of stale blood being obtained. After evacuation of the haematocolpos it was thought that a normal cervix and uterus could be felt at the top of the vagina. The vagina has contracted down and we hope to do a hysterogram on this patient in a few months' time.

-I am, etc.,

\section{Musgrove Park Hospital, Taunton, Somerset. \\ Helen M. Russell.}

\section{Carpal-tunnel Syndrome}

SIR,-I both appreciated and enjoyed the lucid exposition of the carpal-tunnel syndrome by Dr. Hugh Garland and his colleagues (March 2, p. 581). In my experience it is exceptional to elicit neurological signs perhaps from lack of expertise in testing the power of flexor pollicis brevis. The diagnosis is made almost entirely on the history of waking about 4 a.m. with painful tingling in the hand and by examination to exclude cervical spondylosis. $X$-rays of the neck are ignored because radiological changes in the neck bear no constant relationship to the symptoms and signs of cervical spondylosis.

I have found the wrist flexion test the most helpful confirmatory sign of carpal-tunnel compression. If the affected wrist is held fully flexed for a minute or two whilst further history or the range of neck movement are elicited, the typical tingling of median nerve distribution soon supervenes in the majority of cases.

If there is still doubt about the diagnosis the provision of a dorsal plaster slab for night use not only relieves symptoms pending operation but serves as a diagnostic test, since failure of the dorsal slab to give relief suggests that the level of compression neuritis is not at the wrist joint.

I favour the "retinaculotome" for division of the volar carpal ligament, since it can be used through a transverse incision in a wrist crease which after subcuticular suture is invisible. This is open to condemnation as a blind operation, but I take care to pass it at least twice to be sure that the more superficial as well as the deeper fibres of the volar carpal ligament are divided. It is also a wise precaution to pass the instrument upwards in case the constriction is proximal to the volar carpal ligament.-I am, etc.,

$$
\text { Ashford Hospital, }
$$

Ashford, Middlesex.

$$
\text { F. G. WARD. }
$$

\section{The Cost of Bronchitis}

SIR,-With regard to your leading article (March 2, p. 557) on bronchitis may I suggest the need for a Royal Commission to assess the cost of this disease to the country? When one considers the misery, hardship, and financial loss to the individual who suffers from bronchitis and then the cost to the country in terms of lost working hours and the cost of providing expensive hospital beds, and the great cost of the antibiotics used by the medical profession in their endeavours to alleviate the patient's condition and to prolong his miserable life, surely the need for a concerted attack on this disease and the education of the public is vitally necessary. -I am, etc.,

Southsea, Hants.

\section{J. J. BRENNAN.}

\section{College of General Practitioners}

SIR,-At a time when at long last we seem determined to resist the ingratiating and harmful solicitations of the pharmaceutical companies, it is most lamentable that one of our Colleges should have hindered this trend by 